\title{
Association and risk factors of healthcare-associated infection and burden of illness among chemotherapy-induced ulcerative mucositis patients
}

\author{
P. S. Satheeshkumar ${ }^{1,2} \cdot$ M. P. Mohan ${ }^{3}$
}

Received: 26 April 2021 / Accepted: 24 July 2021 / Published online: 6 August 2021

(c) The Author(s), under exclusive licence to Springer-Verlag GmbH Germany, part of Springer Nature 2021

\begin{abstract}
Objectives To evaluate the association and risk factors of healthcare-associated infection (HAI) and burden of illness among chemotherapy-induced ulcerative mucositis (UM) patients.

Methods For this research, US National Inpatient Sample database 2017 was utilized to study UM patients. The association of healthcare-associated infection-related burden of illness among UM patients was assessed on the outcome-length of hospital stays (LOS), total charges, in-hospital mortality, and discharge disposition.

Result In 2017, there were 11,350 adult (> 18 years of age) UM patients, among them there were 415 (3.5\%) HAI. After adjusting for patient and clinical characteristics, UM patients with HAI were most likely to have higher total charges and longer LOS $(1.91 ; 95 \%$ CIs: $1.51-2.41 ; P<0.001 ; 1.84 ; 95 \%$ CIs: $1.53-2.21 ; P<0.001)$ than those without HAI. Further, mortality was not significantly different. UM patients with HAI were less likely to have higher burden of illness who were younger, females, those living in non-metropolitan or micropolitan counties, and those with lower co-morbidity score. Additionally, UM patients with HAI were more likely to discharge to skilled nursing facility (SNF), intermediate care facility (ICF), and another type of facility (ATF), $(\mathrm{aOR}=2.58(1.16-5.76), P=0.02)$, than they were to discharge to self-care or home care.

Conclusion UM patients with HAI were more likely to have higher burden of illness and more likely to discharged to the SNF, ICF, and ATF rather than to home or self-care.

Clinical relevance

UM patients when associated with HAI have higher burden of illness; a tailored approach to oral care might prevent HAIs and burden of illness among UM.
\end{abstract}

\section{Introduction}

Patients undergoing high-dose chemotherapy for solid and hematologic malignancies are anticipated to encounter the adverse events of the chemotherapy [1]. Severe oral

P. S. Satheeshkumar

Satheeshkumar_PoolakkadSankaran@hms.harvard.edu;

Satheesh.Sankaran@ roswellpark.org

M. P. Mohan

minu_mohan@student.uml.edu

1 Harvard Medical School, Boston, MA 02115, USA

2 Department of Oral Oncology, Roswell Park Comprehensive Cancer Center, Buffalo, NY 14263, USA

3 Zuckerberg College of Health Sciences, University of Massachusetts, Lowell, MA 01854, USA mucositis or ulcerative mucositis (UM) is a debilitating adverse event requiring complex management approaches affecting the quality of life of cancer patients [2]. In 2021, 1,898,160 new cancer cases and 608,570 cancer deaths are expected in the United States of America (USA) [3]. Among those receiving standard care chemotherapy as part of cancer management, it is expected that $40 \%$ of them encounter some form of oral mucositis [2]. And those receiving highdose chemotherapy as part of a cancer treatment regimen are expected to face approximately $70 \%$ UM [4-6]. This challenging consequence for cancer patients often results in hospitalization for additional management of UM and associated complications [7]. Reduced oral intake, bleeding, severe pain, and secondary oral infections, in turn, exaggerate the burden of illness by an increased cost of care and length of hospital stay [8-12]. As known, debilitated patients, including patients with cancer, have a high 
likelihood for increased length of stay, leading to hospitalassociated complications comprising healthcare-associated infections (HAI) [11]. At present, association of healthcareassociated infection among UM patients is a gap in knowledge. Conversely, it is necessary to study UM as it leads to negative consequences [13]. Previous studies indicate UM patients are more predisposed to increased length of stay (LOS) and healthcare costs $[14,15]$. Knowingly, UM patients are prone to systemic infections $[16,17]$; the oral cavity is a pool of millions of organisms; increased entry of microorganism to the systemic circulation through mucosal wound among cancer patient undergoing chemotherapy is likely [18-20]. However, systemic infections such as HAI are not studied effectively among those encountering severe adverse events of cancer treatment, such as UM. This study utilized the National Inpatient Sample database to examine the association of the HAI and burden of illness (length of stay, total charges, and discharge disposition) and in-hospital mortality. Further, risk factors associated with HAI and the burden of illness among those encountering chemotherapyinduced UM were evaluated.

\section{Methods}

\section{Study design and data source}

This study was a cross-sectional inpatient database analysis of hospitalized chemotherapy-induced UM patients using discharge data from the 2017 National Inpatient Sample (NIS) database obtained from the Healthcare Cost and Utilization Project (HCUP) of the Agency for Healthcare Research and Quality (AHRQ) [21]. NIS 2017 is organized as $20 \%$ stratified sample of discharges to characterize $97 \%$ of all discharges of US inpatient hospital admissions excluding rehabilitation and long-term acute care hospitals. The NIS dataset comprises patient sociodemographic, comorbidity information, in-hospital outcomes, hospital characteristics, and hospitalization charges. As this analysis was based on publicly available de-identified and anonymous data, this study was exempted by the institutional IRB.

\section{Study population}

This study included patients with chemotherapy-induced ulcerative mucositis in the year 2017. ICD10-CM codes were utilized to identify oral mucositis (ulcerative) due to antineoplastic therapy (K1231). ICD-10-CM billable codes were used to identify hospitalizations with HAI, mainly ventilator-associated pneumonia (VAP), central line-associated bloodstream infection (CLABSI), catheter-associated urinary tract infection (CAUTI), and Clostridium difficile infection (CDI) (supplementary file 1).

\section{Study measurements}

In the study, key independent variable was healthcareassociated infection. The study outcome variables were hospital LOS, total charges, in-hospital mortality, and discharge disposition. LOS was calculated by subtracting the admission date from the discharge date. Total charges included total charge of the health services (in USD)--it includes all hospital utilization fees charged by the hospital and eliminates physician's payments. The outcome, inhospital mortality was defined as mortality that happened during hospitalization coded from discharge disposition of patient (alive or dead). Discharge disposition implies the disposition of the patient at discharge categorized as (1) routine-discharge to home/self-care; (2) short-term hospital; (3) skilled nursing facility, intermediate care, another type of facility; (4) home healthcare, (5) against medical device, and (6) discharge alive, destination unknown.

In the study, 2017 UM cohorts' covariates included were patient level and clinical level characteristics. Patient characteristics included in the study were age, sex (male or female), race (White, Black, Hispanic, Asian or Pacific Islander, Native American, or Other), primary payer (Medicare, Medicaid, private insurance, self-pay, no charge, or other), and median household income based on zip code (first to fourth quartile) and patient's location (urban/rural--using a six-category urban-rural classification scheme for US counties developed by the National Center for Health Statistics) [21]. Clinical characteristics included admission origin (transferred-in, not transferred), transfer type (indicator of a transfer out of the hospital), admission type (elective vs. non-elective; elective indicates whether patients were electively hospitalized), and Elixhauser Comorbidity Index which was used to categorize comorbidities. The Elixhauser Comorbidity Index variables are listed in the HCUP database [22].

\section{Statistical analysis}

Descriptive statistics were used to describe patient and clinical characteristics stratified by UM patients with HAI and without HAI. To account for the complex sampling of the NIS, survey adjusted methods--survey-weighted generalized linear model (Svyglm)--were used to provide original valuations of US population's resulting output [23]. For the total charges and LOS, those were not normally distributed; hence, we log-transformed, and the geometric mean was presented [24]. A value of 0.0001 was imputed for LOS of 0 days to avoid negative $\log$ 
values. A Svyglm was utilized to evaluate the association between HAI status and the outcomes-LOS, total charge, in-hospital mortality, and discharge disposition. Multivariable Svyglm was used to assess the risk factors associated with healthcare-associated infection and burden of illness among chemotherapy-induced ulcerative mucositis patients. The multivariable Svyglm models of LOS, total charges, in-hospital mortality, and discharge disposition were adjusted for the age, sex, payer type, patient location, race, elective, an indicator of a transfer into the hospital, median household income, and comorbidity score. For the in-hospital mortality and discharge dispositions models (binomial), we fitted a family referring quasibinomial to the Svyglm. All analyses were two-tailed and statistical significance was determined using $P<0.05$. All statistical analyses were performed using R 3.5.1 (R Foundation for Statistical Computing, Vienna, Austria).

\section{Results}

In 2017, the NIS documented a total of 11.350 adult ( $>18$ years of age) chemotherapy-induced UM (weightedoriginal patient numbers) discharges from the 7,159,694 (unweighted numbers-20\% of the total patients) patients. There were 415 (3.5\%) of UM patients with HAI. CLABSI represented the highest accounting for $65.8 \%$ of the cases, whereas CDI infections were $30.7 \%$ of the cases, CAUTI were $2.6 \%$ of the cases, and VAP were $0.9 \%$ of the cases. Baseline patient and clinical characteristics are provided in Table 1. There was statistically significant difference between UM patients with and without HAI in terms of age, patient location, and according to transfer out to a different facility.

The geometric mean of the total charge among UM without HAI is 85878 USD, and those with UM with HAI is 170569 USD, $P<0.001$. The adjusted multivariable regression analysis showed that the UM with HAI patients were more likely to have higher total charges (coefficient and confidence interval back transformed from log-transformation: 1.91; 95\% CIs: $1.51-2.41 ; P<0.001)$ than UM patients without HAI. The geometric mean of the LOS among those with UM without HAI is 8.9 days, and for those with UM with HAI is 16.3 days, $P<0.001$. The adjusted multivariable regression analysis showed that the UM with HAI were more likely to have longer LOS (coefficient and confidence interval back transformed from log-transformation: $1.84 ; 95 \%$ CIs: $1.53-2.21 ; P<0.001)$ than UM patients without HAI.

The number and percentage of the mortality among UM patients without HAI are 390 (3.4\%), and those with UM with HAI are 20 (4.8\%), $P=0.47$. In the adjusted analysis, mortality was not significantly different among UM patients with and without HAI, and the adjusted odds ratio (aOR) was $1.59 ; 95 \%$ CIs: $0.57-4.45 ; P=0.37$. For discharge dispositions, UM patients with and without HAI were significantly different $(P<0.001)$. Approximately, 53\% were transferred to the home or self-care, $15.7 \%$ to short-term nursing facility (SNF), intermediate care facility (ICF), and another type of facility (ATF); and $25.3 \%$ to home healthcare, whereas this was $64.8 \%, 7.2 \%$, and $23 \%$ among UM patients without HAI.

Table 2 provides the adjusted regression results for LOS, total charges, and in-hospital mortality. UM with HAI were more likely to have higher total charges and longer LOS. Factors associated with higher total charge among UM patients with HAI were being Hispanic race, having private insurance, elective admission, and those transferred in from different acute care hospitals, whereas females when compared to males, younger age group, those living in nonmetropolitan or micropolitan counties, and having lower comorbidity score were less likely to have higher total charges. Factors associated with longer LOS among UM with HAI included elective admission, transferred in from a different acute care hospital, and those having lower elixir comorbidity score were less likely to have longer LOS. Factor associated with in-hospital mortality among UM patients with HAI were elixir comorbidity score.

Table 3 provides the adjusted regression results for discharge disposition. In the adjusted model, while placing discharge to home/self-care as a reference, those UM patients with HAI were more likely to be discharged to SNF, ICF, or ATF (aOR: 2.58 (1.16-5.76), $P=0.02$ ). Factors associated with discharge to SNF, ICF, or ATF among UM patients with HAI were age, females when compared to males, UM patients transferred in from a different acute care hospital and co-morbidity score. While placing home/self-care as reference, discharge to HHC, there was a non-significant difference between UM patients with and without HAI (aOR: 1.47;95\%CIs: $0.89-2.44 ; \mathrm{P}=0.14$ ). Factors associated with UM with HAI patients transfer to HHC patients were age, co-morbidity score, elective admission type, and those UM patients transferred in from different acute care hospital.

\section{Discussion}

This study indicates that occurrence of at least $1 \mathrm{HAI}$ among UM patients was associated with 1.91 times increase in total charges and 1.84 times increase in hospital LOS when compared to UM patients without HAI. Further, UM patients with HAI compared to without HAI were more likely to discharge to SNF, ICF, or ATF than were home or self-care. However, there was no difference in in-hospital mortality among UM patients with HAI when compared to the UM patients without HAI. 
Table 1 Baseline characteristics of the UM patients—with and without healthcare-associated infection

\begin{tabular}{|c|c|c|c|}
\hline & UM patients without HAI & UM patients with HAI & $P$ value \\
\hline & $11,350(96.5 \%)$ & $415(3.5 \%)$ & \\
\hline AGE (mean (SD)) & $57(15.8)$ & $52.9(18.5)$ & 0.04 \\
\hline $\begin{array}{l}\text { Sex }(\%) \\
\text { Female }\end{array}$ & $5870(51.7)$ & $225(54.2)$ & 0.64 \\
\hline RACE $(\%)$ & & & 0.3 \\
\hline White & $7605(69.4)$ & $280(72.7)$ & \\
\hline Black & $1210(11.0)$ & $30(7.8)$ & \\
\hline Hispanic & $1185(10.8)$ & $40(10.4)$ & \\
\hline Asian or Pacific Islander, Native American, and Other & $955(8.7)$ & $35(9.1)$ & \\
\hline Median household income (based on current year) & & & 0.78 \\
\hline $0-25$ th percentile & $2430(21.8)$ & $85(21.0)$ & \\
\hline 26th to 50th percentile & $2820(25.3)$ & $115(28.4)$ & \\
\hline 51st to 75 th percentile & $2950(26.4)$ & $115(28.4)$ & \\
\hline 76th to 100th percentile & $2960(26.5)$ & $90(22.2)$ & \\
\hline Expected primary payer $(\%)$ & & & 0.90 \\
\hline Medicare & $4200(37.1)$ & $150(36.1)$ & \\
\hline Medicaid & $1545(13.6)$ & $70(16.9)$ & \\
\hline Private insurance & $4955(43.8)$ & $175(42.2)$ & \\
\hline Self-pay, no charge, and other & $625(5.5)$ & $20(4.8)$ & \\
\hline Patient location: NCHS urban-rural code $(\%)$ & & & 0.02 \\
\hline "Central" counties of metro areas of $\geq 1$ million population & $3585(31.7)$ & $120(28.9)$ & \\
\hline "Fringe" counties of metro areas of $\geq 1$ million population & $2955(26.2)$ & $80(19.3)$ & \\
\hline Counties in metro areas of $250,000-999,999$ population & $2310(20.5)$ & $90(21.7)$ & \\
\hline Counties in metro areas of $50,000-249,999$ population & $985(8.7)$ & $20(4.8)$ & \\
\hline Micropolitan counties & $860(7.6)$ & $60(14.5)$ & \\
\hline Not metropolitan or micropolitan counties & $600(5.3)$ & $45(10.8)$ & \\
\hline Admission type (\%) & & & 0.39 \\
\hline Elective & $3780.0(33.3)$ & $155.0(37.3)$ & \\
\hline Indicator of a transfer into the hospital (\%) & & & 0.50 \\
\hline Not transferred in & $10,400(91.8)$ & $375(90.4)$ & \\
\hline Transferred in from a different acute care hospital & $725(6.4)$ & $25(6.0)$ & \\
\hline Transferred in from another type of health facility & $205(1.8)$ & $15(3.6)$ & \\
\hline Weighted Elixir score mean (SD)) & $18.8(13.3)$ & $18.4(15.1)$ & 0.81 \\
\hline Disposition of Patient (No, \%) & & & $<0.001$ \\
\hline Discharge to home/self-care & $7355(64.8)$ & $220(53.0)$ & \\
\hline Skilled nursing facility, intermediate care, another type of facility & $815(7.2)$ & $65(15.7)$ & \\
\hline Home healthcare & $2640.0(23.3)$ & $105(25.3)$ & \\
\hline Length of stay (geometric mean) & 8.9 days & 16.3 days & $<0.001$ \\
\hline Total charge (geometric mean) & 85,878 USD & 170,569 USD (2.9) & $<0.001$ \\
\hline Died (No, \%) & $390(3.4)$ & $20(4.8)$ & 0.47 \\
\hline
\end{tabular}

Abbreviations: $S D$, standard deviation; NCHS, National Center for Health Statistics; UM, chemotherapy-induced UM; HAI, healthcare-associated infection

Note: All frequencies and percentages are weighted

The cohort-chemotherapy-induced UM-comprised a heterogeneous cancer group receiving chemotherapy for both solid and hematologic patients. Hospitalized cancer patients have a high likelihood of infections due to their immunologic competence, which is further complicated by comorbidities or chronic illness. Reports indicate that HAI are a serious concern in the cancer care, and there are no dissimilarities in encountering HAI when considering the solid and hematological malignancies [25]. However, 
Table 2 Factors associated with hospital charge, length of stay, and mortality

\begin{tabular}{|c|c|c|c|}
\hline & \multicolumn{2}{|c|}{$\begin{array}{l}\text { Coefficient and 95\% CIs (back transformed from log } \\
\text { transformation) }\end{array}$} & \multirow{2}{*}{$\begin{array}{l}\text { Adjusted odds ratio (95\% CIs), } P \text { value } \\
\text { Mortality }\end{array}$} \\
\hline & Total charge & Length of stay & \\
\hline \multicolumn{4}{|l|}{ Healthcare-associated infection } \\
\hline UM without HAI & Reference & Reference & Reference \\
\hline UM with HAI & $1.91(1.51-2.41), P<0.001$ & $1.84(1.53-2.21), P<0.001$ & $1.59(0.57-4.45), \mathrm{P}=0.37$ \\
\hline Age & $0.99(0.98-0.99), P=0.004$ & $0.99(0.99-1.00), P=0.14$ & $1.02(0.99-1.04), \mathrm{P}=0.16$ \\
\hline \multicolumn{4}{|l|}{ Sex } \\
\hline Male & Reference & Reference & Reference \\
\hline Female & $0.86(0.78-0.95), P=0.003$ & $0.92(0.84-1.0), P=0.08$ & $0.76(0.48-1.21), \mathrm{P}=0.25$ \\
\hline \multicolumn{4}{|l|}{ Race $(\%)$} \\
\hline White & Reference & Reference & Reference \\
\hline Black & $0.89(0.75-1.07), P=0.23$ & $1.00(0.88-1.15), P=0.91$ & $0.97(0.39-2.29), P=0.89$ \\
\hline Hispanic & $1.31(1.07-1.60), P=0.009$ & $1.05(0.89-1.25), P=0.57$ & $1.46(0.63-3.37), P=0.37$ \\
\hline $\begin{array}{l}\text { Asian or Pacific Islander, Native Ameri- } \\
\text { can, and Other }\end{array}$ & $1.01(0.77-1.33), P=0.94$ & $0.96(0.73-1.25), P=0.76$ & $0.81(0.36-1.83), P=0.61$ \\
\hline \multicolumn{4}{|l|}{ Expected primary payer } \\
\hline Medicare & Reference & Reference & Reference \\
\hline Medicaid & $1.15(0.94-1.42), P=0.15$ & $1.04(0.85-1.31), P=0.61$ & $0.97(0.39-2.38), P=0.94$ \\
\hline Private insurance & $1.15(1.01-1.29), P=0.03$ & $1.04(0.93-1.18), P=0.45$ & $0.92(0.48-1.21), P=0.81$ \\
\hline Self-pay, no charge, and Other & $1.13(0.86-1.49), P=0.38$ & $1.12(0.91-1.38), P=0.29$ & $1.09(0.29-4.02), P=0.89$ \\
\hline \multicolumn{4}{|l|}{ Patient Location: NCHS urban-rural code } \\
\hline $\begin{array}{l}\text { Central counties of metro areas of } \geq 1 \\
\text { million population }\end{array}$ & Reference & Reference & Reference \\
\hline $\begin{array}{l}\text { Fringe counties of metro areas of } \geq 1 \text { mil- } \\
\text { lion population }\end{array}$ & $0.89(0.75-1.06), P=0.19$ & $1.03(0.90-1.17), P=0.66$ & $0.96(0.49-1.89), P=0.92$ \\
\hline $\begin{array}{l}\text { Counties in metro areas of } 250,000- \\
999,999 \text { population }\end{array}$ & $0.84(0.70-0.99), P=0.05$ & $0.98(0.87-1.12), P=0.78$ & $0.79(0.39-1.60), P=0.52$ \\
\hline $\begin{array}{l}\text { Counties in metro areas of } 50,000- \\
249,999 \text { population }\end{array}$ & $0.81(0.66-0.99), P=0.05$ & $1.04(0.88-1.22), P=0.65$ & $1.08(0.44-2.67), P=0.86$ \\
\hline Micropolitan counties & $0.85(0.67-1.08), P=0.18$ & $0.99(0.76-1.27), P=0.91$ & $1.61(0.66-3.91), P=0.29$ \\
\hline $\begin{array}{l}\text { Not metropolitan or micropolitan coun- } \\
\text { ties }\end{array}$ & $0.67(0.52-0.85), P=0.001$ & $0.79(0.58-1.06), P=0.11$ & $0.99(0.31-3.19), P=0.99$ \\
\hline Weighted Elixir score mean & $0.99(0.98-0.99), P=0.009$ & $0.99(0.98-.99), P=0.007$ & 1.05 (1.04-1.07), $P<0.001$ \\
\hline \multicolumn{4}{|l|}{ Admission type } \\
\hline Non-elective & Reference & Reference & Reference \\
\hline Elective & 2.33 (1.99-2.83), $P<0.001$ & $2.03(1.81-2.28), P<0.001$ & $0.51(0.25-1.05), P=0.07$ \\
\hline \multicolumn{4}{|l|}{ Indicator of a transfer into the hospital } \\
\hline Not a transfer & Reference & Reference & Reference \\
\hline $\begin{array}{l}\text { Transferred in from a different acute care } \\
\text { hospital }\end{array}$ & $1.78(1.43-2.22), P<0.001$ & $1.94(1.61-2.36), P<0.001$ & $0.71(0.24-2.07), P=53$ \\
\hline $\begin{array}{l}\text { Transferred in from another type of } \\
\text { health facility }\end{array}$ & $0.93(0.6-1.44) . P=0.75$ & $1.18(0.85-1.67), P=0.32$ & $1.38(0.38-5.19), P=0.61$ \\
\hline \multicolumn{4}{|c|}{ Median household income based on patient's income } \\
\hline $0-25$ th percentile & Reference & Reference & Reference \\
\hline 26th to 50th percentile & $1.13(0.98-1.31), P=0.09$ & $1.08(0.93-1.24), P=0.31$ & $1.53(0.72-3.26), P=0.27$ \\
\hline 51 st to 75 th percentile & $1.13(0.98-1.33), P=0.09$ & $1.08(0.93-1.25), P=0.32$ & $1.48(0.67-3.28), P=0.33$ \\
\hline 76th to 100 th percentile & $1.20(0.99-1.45), P=0.05$ & $1.07(0.91-1.25), P=0.42$ & $1.33(0.58-3.08), P=0.49$ \\
\hline
\end{tabular}

Abbreviations: skilled nursing facility (SNF), intermediate care facility (ICF), and another type of facility, confidence intervals (CIs), odds ratio (OR). Healthcare-associated infection (HAI), ulcerative mucositis (UM) 
Table 3 Factors associated with discharge dispositions

\begin{tabular}{|c|c|c|}
\hline \multirow[t]{3}{*}{ Variables } & \multicolumn{2}{|l|}{ Adjusted odds ratio (95\% CIs), $P$ value } \\
\hline & \multicolumn{2}{|l|}{ Discharge disposition } \\
\hline & $\begin{array}{l}\text { SNF, ICF, and another type of facil- } \\
\text { ity) vs home/self-care }\end{array}$ & Home healthcare vs home/self-care \\
\hline \multicolumn{3}{|l|}{ Healthcare-associated infection status } \\
\hline UM without HAI & Reference & Reference \\
\hline UM with HAI & $2.58(1.16-5.76), P=0.02$ & 1.47 (0.89-2.44), $P=0.14$ \\
\hline Age & 1.05 (1.03-1.08), $P<0.001$ & $1.01(1.00-1.02), P=0.006$ \\
\hline \multicolumn{3}{|l|}{ Sex } \\
\hline Male & Reference & Reference \\
\hline Female & $1.08(0.75-1.57), P=0.68$ & $0.98(0.79-1.24), P=0.89$ \\
\hline \multicolumn{3}{|l|}{ Race $(\%)$} \\
\hline White & Reference & Reference \\
\hline Black & $1.07(0.59-192), P=0.82$ & $0.98(0.72-1.33), P=0.89$ \\
\hline Hispanic & $0.49(0.22-1.08), P=0.08$ & $0.72(0.49-1.04), P=0.08$ \\
\hline Asian or Pacific Islander, Native American, and Other & $0.96(0.41-2.21), P=0.91$ & $0.79(0.41-1.51), P=0.48$ \\
\hline \multicolumn{3}{|l|}{ Expected primary payer } \\
\hline Medicare & Reference & Reference \\
\hline Medicaid & $1.06(0.49-2.29), P=0.88$ & $0.88(0.57-1.35), P=0.56$ \\
\hline Private insurance & $0.59(0.36-0.99), P=0.05$ & $0.75(0.56-1.00), P=0.05$ \\
\hline Self-pay, no charge, Other & $0.66(0.22-1.95), P=0.45$ & $0.45(0.23-0.84), P=0.01$ \\
\hline \multicolumn{3}{|l|}{ Patient location: NCHS urban-rural code } \\
\hline Central counties of metro areas of $\geq 1$ million population & Reference & Reference \\
\hline Fringe counties of metro areas of $\geq 1$ million population & $1.03(0.64-1.67), P=0.89$ & $0.98(0.73-1.31), P=0.87$ \\
\hline Counties in metro areas of $250,000-999,999$ population & $1.25(0.72-2.16), P=0.42$ & $0.76(0.54-1.08), P=0.13$ \\
\hline Counties in metro areas of $50,000-249,999$ population & $0.83(0.36-1.97), P=0.69$ & $0.73(0.47-1.14), P=0.17$ \\
\hline Micropolitan counties & $0.75(0.34-1.66), P=0.48$ & $0.77(0.48-1.23), P=0.27$ \\
\hline Not metropolitan or micropolitan counties & $0.86(0.34-2.21), P=0.76$ & $0.60(0.32-1.13), P=0.11$ \\
\hline Weighted Elixir score mean & 1.05 (1.04-1.06), $P<0.001$ & $1.02(1.00-1.03), P=0.001$ \\
\hline \multicolumn{3}{|l|}{ Admission type } \\
\hline Non-elective & Reference & Reference \\
\hline Elective & $0.53(0.31-0.89), P=0.02$ & $1.45(1.03-2.05), P=0.03$ \\
\hline \multicolumn{3}{|l|}{ Indicator of a transfer into the hospital } \\
\hline Not a transfer & Reference & Reference \\
\hline Transferred in from a different acute care hospital & $2.11(1.12-3.99), P=0.02$ & $1.99(1.33-2.98), P=0.0009$ \\
\hline Transferred in from another type of health facility & $3.59(0.87-14.88), P=0.08$ & $1.48(0.62-3.55), P=0.38$ \\
\hline \multicolumn{3}{|l|}{ Median household income based on patient's income } \\
\hline $0-25$ th percentile & Reference & Reference \\
\hline 26th to 50th percentile & $0.74(0.43-1.29), P=0.29$ & $0.83(0.60-1.14), P=0.25$ \\
\hline 51 st to 75 th percentile & $0.83(0.46-1.48), P=0.52$ & $1.00(0.72-1.40), P=0.98$ \\
\hline 76th to 100th percentile & $0.81(0.43-1.53), P=0.52$ & $1.01(0.71-1.44), P=0.94$ \\
\hline
\end{tabular}

Abbreviations: skilled nursing facility (SNF), intermediate care facility (ICF), and another type of facility, confidence intervals (CIs), odds ratio (OR). Ulcerative mucositis (UM), healthcare-associated infection (HAI)

reports are highly elusive to determine the association of adverse events and HAI among cancer patients.

Expectedly, cancer patients have improved outcome due to better-quality and value-added available therapies; however, as these patients are critically ill, exposed to multiple treatments, and longer hospital days, consequently escalating number of patients are exposed to the HAI [26]. The HAI are paramount concern among cancer patients as they are discharged to facilities for associated symptom management, involving acute care hospitals, ambulatory surgical centers, outpatient care, and long-term care facilities leading to higher financial burden [26-28]. While referring to 
home or self-care, or post-acute care, patients are at risk of infections [26, 27]. HAIs are increasingly common in both developing and developed countries, burden associated with HAI are much higher, and charges associated managing these complications are extremely high. In the USA, the total annual costs for the five major HAIs (CLABSI, CAUTI, CDI, VAP, and surgical site infection) were USD 9.8 billion (95\% CI, 8.3-11.5 billion USD) [28]. Exposure to these infections is fairly predictable in any hospitalized patients, as the risk increases with longer LOS and those are critically ill; identifying high-risk population is an achievable goal for any healthcare facility [28-32]. However, this is very different in the cancer care setting who seek care for infection and sepsis, as the predictability is less due to lack of scoring system and survival prediction [33, 34].

Risk of infection among UM patient may be multifactorial; patients receiving chemotherapy are at risk of neutropenia-a medical emergency if associated with fever (febrile neutropenia) - an early inflammatory response to a serious infection; oral complications of cancer treatment including mucositis might be a high-risk factor for neutropenia [35, 36]. A late response to infection or neutropenic patients unable to respond to systemic infection proceeds to rapidly progressive complications leading to systemic inflammatory response syndrome, sepsis, and septic shock. As explained by Zecha et al., there may be potential contribution by oral sources of infection and inflammation to progress to febrile neutropenia; a potential path of entry to systemic circulation is very likely through oral mucosal wounds, for which a conclusive evidence is still not available [36]. However, salivary gland dysfunction, dysregulation of oral microbiome, pre-existing oral condition, and periodontal disease might contribute to combination of favorable environment for infectious process like febrile neutropenia to progress. Nonetheless, a slow-grade locomotion of HAI causing organisms through mucosal wounds to systemic circulation is exceedingly possible [18-20,37]. As patients undergoing treatment for UM are associated with mild state of neutropenia, and chronic illness, possibility of these HAI causing microorganism growth are manifold [18-20].

Even though there are conflicting arguments on predictors of mucositis, most studies report younger age as strong predictor [38]; nevertheless, along with age studies reported, BMI [39], smoking status [40, 41], neutropenia [42], lymphopenia [43], low hemoglobin levels [43], and renal dysfunction [44] are reported as risk factors. This study showed mean \pm age among UM patients with HAI of 53 years \pm 18.5 , and those without HAI of $57 \pm 15.8$. Higher total charge was associated with UM patients with HAI who were Hispanic race, having private insurance, elective admission, and those transferred in from different acute care hospitals, whereas females when compared to males, younger age, those living in non-metropolitan/micropolitan counties, and having lower comorbidity score were associated with a lower total charge among UM patients with HAI. Among UM patients with HAI, elective admission, and transferred in from different acute care facility were associated with longer LOS, whereas lower comorbidity score was associated with reduced LOS. Comparable to other oral mucositis studies [38, 44, 45], an insight to reflect are UM patients with HAI, who have lower comorbidities, females when compared to males, and young age, are less likely to have a high burden of illness. Conversely, it is known that a higher drug dose is predictably a risk factor for toxicities and related complications, [46] measuring those aspects are limited in the current study.

The post-acute care is an important driver of cost of care, and most Medicare beneficiaries require discharge to postacute care [47-49]. This study noted UM patients with HAI are more likely to discharge to SNF, ICF, and ATF, than to home or self-care. Further, the study showed age, comorbidity score, and elective admission were associated with discharge to SNF, ICF, and ATF than home or self-care. Lately it has been reported that the burden of illness is reduced among those received comfort care from post-acute facilities [50]. Nevertheless, debilitated cancer patients are in need of post-acute care as most are associated with multitude of symptoms and post-acute care referral might benefit from receiving comfort care [51]. We also expect that UM patients with HAI might require symptom management and necessitate and long-term post-acute care. However, from this study, we may not be able to determine the burden of illness among those undergoing post-acute care at other facilities. Evaluating the radiation-induced mucositis and immunotherapyinduced oral mucositis correspondingly is an important issue to be tackled; we are unable to study those aspects due to the nature of the database and further due to the limitation to incorporate additional details in this manuscript.

Infection has been a concern among those undergoing high dose chemotherapy [18-20,36, 52, 53]; a study on infectious complications among those undergoing high-dose chemotherapy for hematologic malignancy reported oral mucositis, and central venous catheter infection has been described to be a most common source of infection [54].

During this COVID-19 pandemic, a report suggests association of COVID-19 severity with duration of mucositis and pain [55]. Contemporary understanding of risk of infectious disease such as COVID-19 among those having severe adverse events of cancer therapy is very limited. This research showed UM patients when affected with HAI have a huge impact by increasing the hospital total charges, length of hospitalization stays, and discharged for care at other facility than self-care or home.

The study findings have many limitations. First, it is likely for one patient to be readmitted and counted more than once as the data is from discharge information. At one point of time, a patient can appear in HAI group and non-HAI group 
at a different point. Second, our cohort was chemotherapyinduced UM patients (without the information of grades) who were treated for care; being said that these are heterogeneous cancer patients having different cancer status and stage, we were unable to account for the effects of these variables in our analyses. Third, we estimated hospital charges rather than true cost; this may vary across hospital systems and also do not include all possible charges incurred such as administrative costs. Fourth, we used ICD-10-codes to identify UM consultation which may be subject to errors. Fifth, we have used the in-hospital mortality rather than the 30-day or 90-day mortality; such information's are available elsewhere. Additionally, the HAIs may be pretentious among radiation-induced UM and immunotherapy-induced $\mathrm{UM}$, the data availability, and inclusion of those pieces are out of scope of this research; however, this research yields a platform how the burden of illness is modified among those with adverse events such as UM and HAI.

\section{Conclusion}

This study showed that burden of illness (LOS, total charge, and discharge dispositions) among UM patients with HAI vs UM patients without HAI are different when covariates are accounted for. However, the in-hospital mortality was not different across the UM patients with and without HAI. UM patients with HAI were younger than UM patients without HAI. Further, higher comorbidity score, elective admission, and transferred in from different acute care hospitals were associated with higher burden of illness among UM with HAI. Utilizing a longitudinal evaluation of cancer treatment adverse events would be an ideal approach in understanding the association of HAI with UM stratified to different cancer cohorts and treatment regimen. As cancer patients are sick, predicting survival and clinical outcome among cancer patients undergoing treatment for infectious complications is tedious due to lack of risk scores. Moreover, the burden of illness associated with HAI among UM patients are compounded by patient and clinical characteristics.

Supplementary Information The online version contains supplementary material available at https://doi.org/10.1007/s00784-021-04106-0.

Acknowledgements Dr. Eric Adjei Boakye, Department of Population Science and Policy, Southern Illinois University School of Medicine, Springfield, IL, for reviewing the entire content and evaluating the statistical methodology.

Authors' contributions Poolakkad S Satheeshkumar had full access to all the data in the study and take responsibility for the integrity of the data and the accuracy of the data analysis. Concept and design: Poolakkad S Satheeshkumar and Minu P Mohan. Acquisition, analysis, or interpretation of data: Poolakkad S Satheeshkumar and Minu P Mohan. Drafting of the manuscript: Poolakkad S Satheeshkumar and Minu P Mohan. Critical revision of the manuscript for important intellectual content: Poolakkad S Satheeshkumar and Minu P Mohan. Statistical analysis: Poolakkad S Satheeshkumar, Minu P Mohan, Supervision: Poolakkad S Satheeshkumar and Minu P Mohan.

Data availability We used data from the 2017 NIS database obtained from Healthcare Cost and Utilization Project (HCUP) of the Agency for Healthcare Research and Quality (AHRQ).

Code availability International Classification of Diseases, Tenth Revision, Clinical Modification (ICD-10-CM) provided in manuscript and in supplementary file 1 and cited in the text. All statistical analyses were performed using R, Version 3.5.1 ( $\mathrm{R}$ foundation for statistical computing, Vienna, Austria).

\section{Declarations}

Ethics approval "This study is a secondary analysis of publicly available de-identified and anonymous data that is considered exempt by the IRB".

Consent to participate Not applicable.

Consent for publication Not applicable.

Conflict of interest The authors declare that they have no conflict of interest.

\section{References}

1. Lalla RV, Sonis ST, Peterson DE (2008) Management of oral mucositis in patients who have cancer. Dent Clin North Am. 52(1):61-77. https://doi.org/10.1016/j.cden.2007.10.002

2. Berger K, Schopohl D, Bollig A, Strobach D, Rieger C, Rublee D, Ostermann H (2018) Burden of oral mucositis: a systematic review and implications for future research. Oncol Res Treat 41(6):399-405. https://doi.org/10.1159/000487085

3. Siegel RL, Miller KD, Fuchs HE, Jemal A (2021) Cancer Statistics, 2021. CA Cancer J Clin 71(1):7-33. https://doi.org/10.3322/ caac. 21654

4. Wang EH, Chen YA, Corringham S, Bashey A, Holman P, Ball ED, Carrier E (2004) High-dose CEB vs BEAM with autologous stem cell transplant in lymphoma. Bone Marrow Transplant 34(7):581-587. https://doi.org/10.1038/sj.bmt.1704637

5. Elting LS, Keefe DM, Sonis ST, Garden AS, Spijkervet FK, Barasch A et al (2008) Burden of Illness Head and Neck Writing Committee. Patient-reported measurements of oral mucositis in head and neck cancer patients treated with radiotherapy with or without chemotherapy: demonstration of increased frequency, severity, resistance to palliation, and impact on quality of life. Cancer 113(10):2704-13. https://doi.org/10.1002/cncr.23898

6. Pfister DG, Spencer S, Brizel DM, Burtness B, Busse PM, Caudell JJC et al (2015) Head and Neck Cancers, Version 1.2015. J Natl Compr Canc Netw 13(7):847-55. https://doi.org/10.6004/jnccn. 2015.0102

7. Lalla RV, Saunders DP, Peterson DE (2014) Chemotherapy or radiation-induced oral mucositis. Dent Clin North Am 58(2):341349. https://doi.org/10.1016/j.cden.2013.12.005

8. Sanctis De V, Bossi P, Sanguineti G, Trippa F, Ferrari D, Bacigalupo A et al (2016) Mucositis in head and neck cancer patients treated with radiotherapy and systemic therapies: literature review 
and consensus statements. Crit Rev Oncol Hematol 100:147-166. https://doi.org/10.1016/j.critrevonc.2016.01.010

9. Carlotto A, Hogsett VL, Maiorini EM, Razulis JG, Sonis ST (2013) The economic burden of toxicities associated with cancer treatment: review of the literature and analysis of nausea and vomiting, diarrhoea, oral mucositis and fatigue. Pharmacoeconomics 31(9):753-766. https://doi.org/10.1007/s40273-013-0081-2

10. Dodd MJ, Dibble S, Miaskowski C, Paul S, Cho M, MacPhail L, Greenspan D, Shiba G (2001) A comparison of the affective state and quality of life of chemotherapy patients who do and do not develop chemotherapy-induced oral mucositis. J Pain Symptom Manage 21(6):498-505. https://doi.org/10.1016/s0885-3924(01) 00277-9

11. Cornejo-Juárez P, Vilar-Compte D, Pérez-Jiménez C, ÑamendysSilva SA, Sandoval-Hernández S, Volkow-Fernández P (2015) The impact of hospital-acquired infections with multidrug-resistant bacteria in an oncology intensive care unit. Int J Infect Dis 31:31-34. https://doi.org/10.1016/j.ijid.2014.12.022

12. Barkokebas A, Silva IH, de Andrade SC, Carvalho AA, Gueiros LA, Paiva SM, Leão JC (2015) Impact of oral mucositis on oralhealth-related quality of life of patients diagnosed with cancer. J Oral Pathol Med 44(9):746-751. https://doi.org/10.1111/jop. 12282

13. Cheng KK, Lee V, Li CH, Yuen HL, Ip WY, He HG, Epstein JB (2013) Impact of oral mucositis on short-term clinical outcomes in paediatric and adolescent patients undergoing chemotherapy. Support Care Cancer 21(8):2145-2152. https://doi.org/10.1007/ s00520-013-1772-0

14. Elting LS, Cooksley CD, Chambers MS, Garden AS (2007) Risk, outcomes, and costs of radiation-induced oral mucositis among patients with head-and-neck malignancies. Int J Radiat Oncol Biol Phys 68(4):1110-1120. https://doi.org/10.1016/j.ijrobp.2007.01. 053

15. Nonzee NJ, Dandade NA, Patel U, Markossian T, Agulnik M, Argiris A et al (2008) Evaluating the supportive care costs of severe radiochemotherapy-induced mucositis and pharyngitis: results from a Northwestern University Costs of Cancer Program pilot study with head and neck and nonsmall cell lung cancer patients who received care at a county hospital, a Veterans Administration hospital, or a comprehensive cancer care center. Cancer 113(6):1446-1452. https://doi.org/10.1002/cncr.23714

16. Sampson MM, Nanjappa S, Greene JN (2017) Mucositis and oral infections secondary to gram negative rods in patients with prolonged neutropenia. IDCases 9:101-103. https://doi.org/10.1016/j. idcr.2017.06.014

17. Shah N, Jacob JA, Natalia LM, Asha R, John GN (2019) Infectious complications of mucositis in postchemotherapy neutropenic cancer patients. Infect Dis Clin Pract 27(5):247-250. https://doi. org/10.1097/IPC.0000000000000762

18. Sotiropoulos SV, Jackson MA, Woods GM, Hicks RA, Cullen J, Freeman AI (1989) Alpha-streptococcal septicemia in leukemic children treated with continuous or large dosage intermittent cytosine arabinoside. Pediatr Infect Dis J 8(11):755-758. https://doi. org/10.1097/00006454-198911000-00005

19. Cohen J, Donnelly JP, Worsley AM, Catovsky D, Goldman JM, Galton DA. Septicaemia caused by viridans streptococci in neutropenic patients with leukaemia. Lancet. 1983 Dec 24-31;2(836566):1452-4. https://doi.org/10.1016/s0140-6736(83)90799-7

20. Burden AD, Oppenheim BA, Crowther D, Howell A, Morgenstern GR, Scarffe JH, Thatcher N (1991) Viridans streptococcal bacteraemia in patients with haematological and solid malignancies. Eur J Cancer 27(4):409-411. https://doi.org/10.1016/02775379(91)90373-1

21. HCUP-US. NIS Overview. https://www.hcup-us.ahrq.gov/nisov erview.jsp. Accessed February 25, 2020
22. Elixhauser A, Steiner C, Harris DR, Coffey RM (1998) Comorbidity measures for use with administrative data. Med Care 36(1):8-27. https://doi.org/10.1097/00005650-19980 1000-00004

23. Lumley T. 2019. survey: Analysis of Complex Survey Samples. URL: https://CRAN.R-project.org/package=survey (Accessed 04/09/2020)

24. Bland JM, Altman DG (1996) Transformations, means, and confidence intervals. BMJ 312:1079

25. Cornejo-Juárez P, Vilar-Compte D, García-Horton A, LópezVelázquez M, Namendys-Silva S, Volkow-Fernández P (2016) Hospital-acquired infections at an oncological intensive care cancer unit: differences between solid and hematological cancer patients. BMC Infect Dis 10(16):274. https://doi.org/10.1186/ s12879-016-1592-1

26. Battaglia CC, Hale K (2019) Hospital-acquired infections in critically ill patients with cancer. J Intensive Care Med 34(7):523-536. https://doi.org/10.1177/0885066618788019

27. Kostakou E, Rovina N, Kyriakopoulou M, Koulouris NG, Koutsoukou A (2014) Critically ill cancer patient in intensive care unit: issues that arise. J Crit Care 29(5):817-822. https://doi.org/10. 1016/j.jcrc.2014.04.007

28. Zimlichman E, Henderson D, Tamir O et al (2013) Health careassociated infections: a meta-analysis of costs and financial impact on the US health care system. JAMA Intern Med 173:2039-2046

29. Hoffman GJ, Min LC, Liu H, Marciniak DJ, Mody L (2020) Role of post-acute care in readmissions for preexisting healthcareassociated infections. J Am Geriatr Soc 68(2):370-378. https:// doi.org/10.1111/jgs. 16208

30. Haukland EC, von Plessen C, Nieder C, Vonen B (2017) Adverse events in hospitalised cancer patients: a comparison to a general hospital population. Acta Oncol 56(9):1218-1223. https://doi.org/ 10.1080/0284186X.2017.1309063

31. Magill SS, Edwards JR, Bamberg W et al (2014) Emerging Infections Program Healthcare-Associated Infections and Antimicrobial Use Prevalence Survey Team. Multistate point-prevalence survey of health care-associated infections. N Engl J Med 370:1198-1208

32. Schmier JK, Hulme-Lowe CK et al (2016) Estimated hospital costs associated with preventable health care-associated infections if healthcare antiseptic products were unavailable. Clinicoecon Outcomes Res 8:197-205

33. Biskup E, Cai F, Vetter M, Marsch S (2017) Oncological patients in the intensive care unit: prognosis, decision-making, therapies and end-of-life care. Swiss Med Wkly 14(147):w14481. https:// doi.org/10.4414/smw.2017.14481

34. Torres VB, Vassalo J, Silva UV, Caruso P, Torelly AP, Silva E, Teles JM, Knibel M, Rezende E, Netto JJ, Piras C, Azevedo LC, Bozza FA, Spector N, Salluh JI, Soares M (2016) Outcomes in Critically Ill Patients with Cancer-Related Complications. PLoS ONE 11(10):e0164537. https://doi.org/10.1371/journal.pone. 0164537

35. Blijlevens NM, Donnelly JP, Pauwde BE (2001) Empirical therapy of febrile neutropenic patients with mucositis: challenge of riskbased therapy. Clin Microbiol Infect 7(Suppl 4):47-52. https:// doi.org/10.1046/j.1469-0691.2001.00058.x

36. Zecha JAEM, Raber-Durlacher JE, Laheij AMGA, Westermann AM, Epstein JB, de Lange J, Smeele LE (2019) The impact of the oral cavity in febrile neutropenia and infectious complications in patients treated with myelosuppressive chemotherapy. Support Care Cancer 27(10):3667-3679. https://doi.org/10.1007/ s00520-019-04925-8

37. Färkkilä E, Rautemaa-Richardson R, Färkkilä A, Grönholm L, Lauhio A (2019) Evaluation of risk factors for oral infection with potential for spread in a 1-year cohort study. Clin Oral Investig 23(2):905-911. https://doi.org/10.1007/s00784-018-2518-7 
38. Morais-Faria K, Palmier NR, de Lima CJ, de Castro JG, Dias RB, da Graça PH, Lopes MA, Ribeiro ACP, Brandão TB, Santos-Silva AR (2020) Young head and neck cancer patients are at increased risk of developing oral mucositis and trismus. Support Care Cancer 28(9):4345-4352. https://doi.org/10.1007/ s00520-019-05241-x

39. Wardill HR, Sonis ST, Blijlevens NMA, Van Sebille YZA, Ciorba MA, Loeffen EAH, Cheng KKF, Bossi P, Porcello L, Castillo DA, Elad S, Bowen JM (2020) Mucositis Study Group of the Multinational Association of Supportive Care in Cancer/International Society of Oral Oncology (MASCC/ISOO). Prediction of mucositis risk secondary to cancer therapy: a systematic review of current evidence and call to action. Support Care Cancer 28(11):5059-5073. https://doi.org/10.1007/s00520-020-05579-7

40. Shouval R, Kouniavski E, Fein J, Danylesko I, Shem-Tov N, Geva M, Yerushalmi R, Shimoni A, Nagler A (2019) Risk factors and implications of oral mucositis in recipients of allogeneic hematopoietic stem cell transplantation. Eur J Haematol 103:402-409. https://doi.org/10.1111/ejh.13299

41. Tao Z, Gao J, Qian L, Huang Y, Zhou Y, Yang L, He J, Yang J, Wang R, Zhang Y (2017) Factors associated with acute oral mucosal reaction induced by radiotherapy in head and neck squamous cell carcinoma: a retrospective single-center experience. Medicine 96(50):e8446. https://doi.org/10.1097/md.0000000000 008446

42. Reyna-Figueroa J, Garcia-Beristain JC, Galindo-Delgado P, Limon-Rojas AE, Madrid-Marina V (2015) Antibiotic use before chemotherapy: a risk factor for developing neutropenic colitis in children with leukemia. J Pediatr Hematol Oncol 37(2):121-127. https://doi.org/10.1097/mph.000000000000027

43. Nishii M, Soutome S, Kawakita A, Yutori H, Iwata E, Akashi M, Hasegawa T, Kojima Y, Funahara M, Umeda M, Komori T (2019) Factors associated with severe oral mucositis and candidiasis in patients undergoing radiotherapy for oral and oropharyngeal carcinomas: a retrospective multicenter study of 326 patients. Supportive care in cancer: official journal of the Multinational Association of Supportive Care in Cancer 28:1069-1075

44. Mizuno H, Miyai H, Yokoi A, Kobayashi T, Inabu C, Maruyama T, Ekuni D, Mizukawa N, Kariya S, Nishizaki K, Kimata Y, Morita M (2019) Relationship between renal dysfunction and oral mucositis in patients undergoing concurrent chemoradiotherapy for pharyngeal cancer: a retrospective cohort study. vivo (Athens, Greece) 33(1):183-189

45. Vokurka S, Bystricka E, Koza V, Scudlova J, Pavlicova V, Valentova D, Visokaiova M, Misaniova L (2006) Higher incidence of chemotherapy induced oral mucositis in females: a supplement of multivariate analysis to a randomized multicentre study. Supportive care in cancer: official journal of the Multinational Association of Supportive Care in Cancer 14(9):974-976. https://doi.org/10. 1007/s00520-006-0031-z
46. Barnett GC, De Meerleer G, Gulliford SL, Sydes MR, Elliott RM, Dearnaley DP (2011) The impact of clinical factors on the development of late radiation toxicity: results from the Medical Research Council RT01 trial (ISRCTN47772397). Clin Oncol (Royal College of Radiologists (Great Britain)) 23(9):613-624. https://doi.org/10.1016/j.clon.2011.03.001

47. Mechanic R (2014) Post-acute care-the next frontier for controlling Medicare spending. N Engl J Med 370(8):692-694. https:// doi.org/10.1056/NEJMp1315607

48. Christakis NA, Escarce JJ (1996) Survival of Medicare patients after enrollment in hospice programs. N Engl J Med 335(3):172-178

49. Sesterhenn AM, Folz BJ, Bieker M, Teymoortash A, Werner JA (2008) End-of-life care for terminal head and neck cancer patients. Cancer Nurs 31(2):E40-E46

50. Schorr CA, Angelo M, John G, LeCompte K, Dellinger RP (2020) The Association of Increasing Hospice Use With Decreasing Hospital Mortality: an Analysis of the National Inpatient Sample. J Healthc Manag 65(2):107-120. https://doi.org/10.1097/ JHM-D-18-00280

51. Daugherty C, Johnson J, Levine SK et al (2019) Lower costs of care, improved discharge disposition, and improved survival of advanced cancer patients (ACP) receiving early inpatient palliative care (PC) compared to standard oncologic care(SOC). J Clin Oncol 37(15_suppl):11609-11609. https://doi.org/10.1200/JCO. 2019.37.15_suppl.11609

52. Ohbayashi Y, Imataki O, Uemura M, Takeuchi A, Aoki S, Tanaka M, Nakai Y, Nakai F, Miyake M (2021) Oral microorganisms and bloodstream infection in allogeneic hematopoietic stem cell transplantation. Clin Oral Investig. https://doi.org/10.1007/ s00784-020-03749-9

53. Alonso CD, Dufresne SF, Hanna DB, Labbé AC, Treadway SB, Neofytos D, Bélanger S, Huff CA, Laverdière M, Marr KA (2013) Clostridium difficile infection after adult autologous stem cell transplantation: a multicenter study of epidemiology and risk factors. Biol Blood Marrow Transplant 19(10):1502-1508. https:// doi.org/10.1016/j.bbmt.2013.07.022

54. Madani TA (2000) Clinical infections and bloodstream isolates associated with fever in patients undergoing chemotherapy for acute myeloid leukemia. Infection 28(6):367-373. https://doi.org/ $10.1007 / \mathrm{s} 150100070007$

55. Riad A, Kassem I, Badrah M, Klugar M (2020) The manifestation of oral mucositis in COVID-19 patients: A case-series. Dermatol Ther 33(6):e14479. https://doi.org/10.1111/dth.14479

Publisher's note Springer Nature remains neutral with regard to jurisdictional claims in published maps and institutional affiliations. 